\title{
Mecp2 Deficiency Disrupts Norepinephrine and Respiratory Systems in Mice
}

\author{
Jean-Charles Viemari, ${ }^{1 *}$ Jean-Christophe Roux, ${ }^{2 *}$ Andrew K. Tryba, ${ }^{1,7}$ Véronique Saywell, ${ }^{2}$ Henri Burnet, ${ }^{3}$ \\ Fernando Peña, ${ }^{1,4}$ Sébastien Zanella, ${ }^{3}$ Michelle Bévengut, ${ }^{3}$ Magali Barthelemy-Requin, ${ }^{3}$ Laura B. K. Herzing, ${ }^{5}$ \\ Anne Moncla, ${ }^{2}$ Josette Mancini, ${ }^{6}$ Jan-Marino Ramirez, ${ }^{1}$ Laurent Villard, ${ }^{2}$ and Gérard Hilaire ${ }^{3}$ \\ ${ }^{1}$ Department of Organismal Biology and Anatomy, The University of Chicago, Chicago, Illinois 60637, ${ }^{2}$ Institut National de la Santé et de la Recherche \\ Médicale, Unité 491, Faculté de Médecine de la Timone, Université de la Méditerrannée, 13385 Marseille Cedex 5, France, ${ }^{3}$ Centre National de la Recherche \\ Scientifique, Formation de Recherche en Evolution 2722, Groupe d’Etude des Réseaux Moteurs, Université de la Méditerrannée, 13009 Marseille, France, \\ ${ }^{4}$ Departamento de Farmacobiología, Centro de Investigación y Estudios Avanzados, 14330 Mexico Distrito Federal, Mexico, ${ }^{5}$ Northwestern University \\ Feinberg School of Medicine, Program in Human and Molecular Genetics, Children's Memorial Institute for Education and Research, Chicago, Illinois \\ 60614, ${ }^{6}$ Département de Neurologie Pédiatrique, Hôpital d’Enfants de La Timone, 13385 Marseille Cedex 5, France, and Department of Physiology, Medical \\ College of Wisconsin, Milwaukee, Wisconsin 53226
}

Rett syndrome is a severe $\mathrm{X}$-linked neurological disorder in which most patients have mutations in the methyl-CpG binding protein 2 (MECP2) gene and suffer from bioaminergic deficiencies and life-threatening breathing disturbances. We used in vivo plethysmography, in vitro electrophysiology, neuropharmacology, immunohistochemistry, and biochemistry to characterize the consequences of the MECP2 mutation on breathing in wild-type (wt) and Mecp2-deficient (Mecp2-/y) mice. At birth, Mecp2-/y mice showed normal breathing and a normal number of medullary neurons that express tyrosine hydroxylase (TH neurons). At $\sim 1$ month of age, most Mecp2-/y mice showed respiratory cycles of variable duration; meanwhile, their medulla contained a significantly reduced number of TH neurons and norepinephrine (NE) content, even in Mecp2-/y mice that showed a normal breathing pattern. Between 1 and 2 months of age, all unanesthetized Mecp2-/y mice showed breathing disturbances that worsened until fatal respiratory arrest at $\sim 2$ months of age. During their last week of life, Meсp2-/y mice had a slow and erratic breathing pattern with a highly variable cycle period and frequent apneas. In addition, their medulla had a drastically reduced number of TH neurons, NE content, and serotonin (5-HT) content. In vitro experiments using transverse brainstem slices of mice between 2 and 3 weeks of age revealed that the rhythm produced by the isolated respiratory network was irregular in Mecp2-/y mice but could be stabilized with exogenous NE. We hypothesize that breathing disturbances in Mecp2-/y mice, and probably Rett patients, originate in part from a deficiency in noradrenergic and serotonergic modulation of the medullary respiratory network.

Key words: Mecp2 gene; respiration; norepinephrine; A1/C1 neurons; A2/C2 neurons; Rett syndrome

\section{Introduction}

Rett syndrome is a severe neurological disorder, which may account for up to $10 \%$ of the cases of severe mental retardation of

\footnotetext{
Received April 6, 2005; revised 0ct. 13, 2005; accepted 0ct. 22, 2005.

This study was supported by Centre National de la Recherche Scientifique Grant Formation de Recherche en Evolution 2722, French Ministry for Research Grant Action Concertée Incitative NIC0054, the Association Française du Syndrome de Rett (AFSR), the University of Méditerranée and Rett Syndrome Research Foundation (RSRF), the Institut National de la Santé et de la Recherche Médicale and Region Provence-Alpes-Côte d'Azur (V.S.), AFSR and RSRF (J.-C.R., S.Z.), International Rett Syndrome Association (L.B.K.H.), National Institutes of Health Grants HL 68860 and 60120 (J.-M.R.), the Parker B. Francis Fellowship (A.K.T.), a Pew Postdoctoral Fellowship (F.P.), and the Philippe Foundation (J.-C.V.). We thank Marie Gardette for figure assistance and Celine Beccaris for genotyping and animal care. We also thank Dr. Andrew A. Hill and Michael S. Carroll for critically reading this manuscript and carefully checking for errors. We also thank Monica Coenraads and RSRF for continued help and enthusiastic support throughout this study, and we dedicate this work to all Rett syndrome children that continue to suffer from major breathing problems.

*J.-C.V. and J.-C.R. contributed equally to this work.

Correspondence should be addressed to Jan-Marino Ramirez, Department of Organismal Biology and Anatomy, University of Chicago, 1027 East 57th Street, Chicago, IL 60637. E-mail: jramire@uchicago.edu.

DOI:10.1523/JNEUROSCI.4373-05.2005

Copyright $\odot 2005$ Society for Neuroscience 0270-6474/05/2511521-10\$15.00/0
}

genetic origin in women (Armstrong, 1997). Although a few familial cases have been reported, most of the cases are sporadic and are frequently (80-90\%) associated with mutations in the methyl-CpG binding protein 2 (MECP2) gene (Van den Veyver and Zoghbi, 2000; Ravn et al., 2005). Rett patients develop normally until 6-18 months of age. Thereafter, they suffer from a number of neurological symptoms, including regression of acquisitions, behavioral disturbances with stereotypic hand movements (Hagberg et al., 1983), and severe breathing irregularities (Elian and Rudolf, 1991; Kerr, 1992; Woodyatt and Murdoch, 1996; Morton et al., 1997; Cooper et al., 1998; Kerr and Julu, 1999; Julu et al., 2001). Twenty-six percent of deaths in girls with Rett syndrome are attributed to sudden respiratory arrhythmia (Kerr et al., 1997). This breathing arrhythmia has puzzled clinicians because of its state dependency. Breathing is regular during sleep but can switch from highly irregular to regular during wakefulness (Marcus et al., 1994; Julu, 2001). Because breathing can at times be regular, many clinicians believe that these breathing problems are a consequence of disturbed cortical rather than 
brainstem mechanisms (Marcus et al., 1994) and may thus be behaviorally determined (Elian and Rudolf, 1991). Here, we propose that these breathing irregularities are caused by a lack of neuromodulators required for generating regular respiratory rhythms in the brainstem. Indeed, disturbances in neuromodulators have in the past been proposed to explain Rett syndrome, but no definitive conclusions have been reached (Nomura et al., 1985; Zoghbi et al., 1985, 1989; Riederer et al., 1986; Lekman et al., 1990; Nielsen et al., 1990; Segawa, 1997; Kerr et al., 1998; Dunn, 2001; Dunn and MacLeod, 2001). Considering the key role that norepinephrine (NE) plays in the maturation and modulation of the respiratory network (Hilaire et al., 2004; Viemari et al., 2004, 2005), the fact that metabolites of NE are found at reduced levels in Rett patients (Zoghbi et al., 1985, 1989) is a particularly important finding.

To address this neuromodulator hypothesis in more detail, we studied the relationship between NE and the respiratory system in mice in which the Mecp 2 gene had been inactivated (Guy et al., 2001). Using a multilevel approach, we found that Mecp2-/y mice have a deficiency in NE and 5-HT content in the medulla and a drastic reduction of medullary $\mathrm{TH}$ neurons. In vivo experiments revealed breathing disturbances that began after 1 month of age and were characterized by a highly variable cycle period and frequent apneas that worsened over time. Parallel in vitro experiments showed that animals $<1$ month of age already express an irregular fictive respiratory rhythm that could be stabilized by the addition of exogenous NE. We propose that MECP2 deficiency leads to severe respiratory disturbances that may be mediated by neuromodulatory disturbances, which include a disruption of the noradrenergic and serotonergic systems.

\section{Materials and Methods}

Animals breeding and genotyping. Experiments were performed on mice using the mouse model [strain B6.129P2(C)-Mecp2 tm1-1Bird] for Rett syndrome developed by Prof. Adrian Bird (Wellcome Trust Centre for Cell Biology, Institute of Cell and Molecular Biology, University of Edinburgh, Edinburgh, UK) (Guy et al., 2001). The mice were obtained from The Jackson Laboratory (Bar Harbor, ME) and maintained on a C57BL/6 background. Hemizygous mutant Mecp2 males were generated by crossing heterozygous knock-out females with C57BL/6 males. All of our experiments were performed in hemizygous Mecp 2 males. Although Rett syndrome in humans affects female patients, most researchers use Mecp2-/y male mice for their studies. This choice is dictated by the fact that the Mecp2 gene is X-linked in mice and humans, and females will thus have a different amount of normally Mecp2-expressing cells depending on their X-chromosome inactivation profile. Because this produces an unpredictable and heterogenous phenotype in female mutants, we decided to use Mecp2-/y male mice, assuring the complete absence of the Mecp2 gene product in all cells (i.e., a real null phenotype). Genotyping was performed by routine PCR technique according to The Jackson Laboratory protocols. The experimental procedures were performed in keeping with European guidelines for the care and use of laboratory animals (Council Directive 86/6009/EEC) and with The Institutional Animal Care and Use Committee at The University of Chicago. Unless otherwise stated, all of the chemical compounds were obtained from Sigma (St. Louis, MO and St. Quentin, France).

Plethysmographic recording of mouse breathing patterns. As reported previously in detail (Burnet et al., 2001; Viemari et al., 2004), the breathing patterns were recorded from unrestrained mice by whole-body barometric plethysmography. The animal and reference chambers (200 and $25 \mathrm{ml}$ for adult and young mice, respectively) were immersed in a temperature-regulated water bath and maintained at $26-28^{\circ} \mathrm{C}$ (temperature sensor Checktemp 1; Hanna Instruments, Lingolsheim, France). The spirogram was obtained by recording the pressure difference between the two chambers (Validyne CD 15; frequency response, DC to $1000 \mathrm{~Hz}$; Validyne, Northbridge, CA). The signal was amplified, filtered
(DC-50 Hz), fed to an analog-to-digital converter (sampling frequency, 1 $\mathrm{kHz}$ ), and stored on a personal computer disk via the Spike 2 interface and software (Cambridge Electronic Design, Cambridge, UK). For each mouse, successive 3 min plethysmographic measurements were performed until the animal was quiet (i.e., without limb, body, and head movements). Only the recording periods during which the animals were quiet were analyzed. The total respiratory cycle duration $\left(T_{\mathrm{TOT}}\right)$ and the tidal volume $\left(V_{\mathrm{T}}\right)$ were measured for each cycle from a recording of a 100 consecutive respiratory cycles. In the figures, $V_{\mathrm{T}}$ values were normalized as the ratio of the $V_{\mathrm{T}}$ divided by the body weight $\left(V_{\mathrm{T}} / B\right)$. The measurements were interrupted every $3 \mathrm{~min}$ to flush the animal chamber with air for $1 \mathrm{~min}$. Controls performed in some experiments showed that oxygen and carbon dioxide fractions were normal in the animal chamber (Portable Gaz Analyzer KG850; Hitech Instruments, Luton, UK). During ongoing experiments, breathing was recorded in a whole-body flow plethysmograph (EMKA Technologies, Paris, France) in which a constant flow pump connected to the animal chamber ensured proper and continuous inflow of fresh air, avoiding interruption of recording to flush air in the animal chamber. Similar results were obtained in Mecp2-/y mice with both types of plethysmograph. To test the effect of anesthesia on breathing of Mecp2-/y mice, some plethysmographic recordings were performed in lightly anesthetized Mecp2-/y mice, which received half surgical doses of sodium pentobarbitone $\left(30 \mathrm{mg} \mathrm{kg}^{-1}\right.$ i.p.; Sanofi, Libourne, France).

In vitro electrophysiological study of the medullary respiratory network in young mice. Experiments were performed on wt and Mecp2-/y mice at postnatal day 14 (P14) to $\mathrm{P} 21$ using a slice preparation technique previously described in detail (Peña and Ramirez, 2002). Throughout the experiments, the experimenter was blind to the mouse genotype. Briefly, the animals were decapitated under ether anesthesia, and the isolated brainstem was placed in ice-cold artificial CSF (ACSF) bubbled with carbogen $\left(95 \% \mathrm{O}_{2}\right.$ and $\left.5 \% \mathrm{CO}_{2}\right)$. The ACSF contained the following (in m) : $128 \mathrm{NaCl}, 3 \mathrm{KCl}, 1.5 \mathrm{CaCl}_{2}, 1 \mathrm{MgCl}_{2}, 24 \mathrm{NaHCO}_{3}, 0.5 \mathrm{NaH}_{2} \mathrm{PO}_{4}$, and $30 \mathrm{D}$-glucose, $\mathrm{pH}$ 7.4. The brainstem was glued rostral end up onto an agar block, mounted into a vibratome (Leica Microsystems, Waukegan, IL), and serially sliced until disappearance of the facial nucleus and appearance of the inferior olive, the nucleus ambiguus, and the hypoglossal nucleus. A single 650- $\mu \mathrm{m}$-thick slice was then taken and used for study. We refer to the area encompassed in the slice as the ventral respiratory group (VRG). Slices were transferred into a recording chamber, continuously superfused with oxygenated ACSF, and maintained at a temperature of $29 \pm 0.5^{\circ} \mathrm{C}$. To initiate and maintain fictive respiratory rhythmic activity, the potassium concentration of the perfusate was raised from 3 to $8 \mathrm{~mm}$ over $30 \mathrm{~min}$ (Tryba et al., 2003). The population activity from the VRG neurons was recorded with suction electrodes positioned on the surface of the slice and was used as a marker for inspiratory activity. The signals were amplified, filtered (low pass, $1.5 \mathrm{kHz}$; high pass, $250 \mathrm{~Hz}$ ), rectified, and integrated (time constant, $60 \mathrm{~ms}$ ). All recordings were stored on a computer using AxoTape (version 2.0; Molecular Devices, Union City, CA) and analyzed off-line using customized analysis software written with IGOR Pro (Wavemetrics, Lake Oswego, OR). In some experiments, $20 \mu \mathrm{M}$ NE was added to carbogenated ACSF. The normal ACSF was changed to ACSF containing $20 \mu \mathrm{M} \mathrm{NE}$ for 5-10 min, and the resulting alterations in frequency and stability of VRG bursts were analyzed as reported below.

Biochemical analysis. Twelve Mecp2-/y mice and $18 \mathrm{wt}$ mice were killed with a lethal pentobarbitone injection (300 $\mathrm{mg} \mathrm{kg}^{-1}$, i.p.), and their brains were dissected out within $5 \mathrm{~min}$ of their last breaths. The forebrain, pons, and medulla were separated, weighed, and kept at $-80^{\circ} \mathrm{C}$ until biochemical analysis. Each sample was homogenized in cold trichloroacetic acid ( $5 \%$ in $\mathrm{H}_{2} \mathrm{O} ; 200 \mu \mathrm{l}$ for pons and medulla; $1000 \mu \mathrm{l}$ for forebrain) with a micropotter. The cellular suspension was then centrifuged $\left(10 \mathrm{~min}, 600 \times g, 5^{\circ} \mathrm{C}\right)$, and the supernatant was collected and diluted by adding a volume of an antioxidant solution $(0.65 \mathrm{~mm}$ ascorbic acid and 0.35 mM EDTA in $\mathrm{H}_{2} \mathrm{O}$ ) corresponding to one-fifth of the supernatant volume. HPLC (UVK Laboratory, Paris, France) coupled with electrochemical detection was used to measure the endogenous concentrations of NE, 5-HT, dopamine, and the main 5-HT metabolite 5-hydroxyindole-3-acetic acid (5HIAA). The carbon electrode was at a 

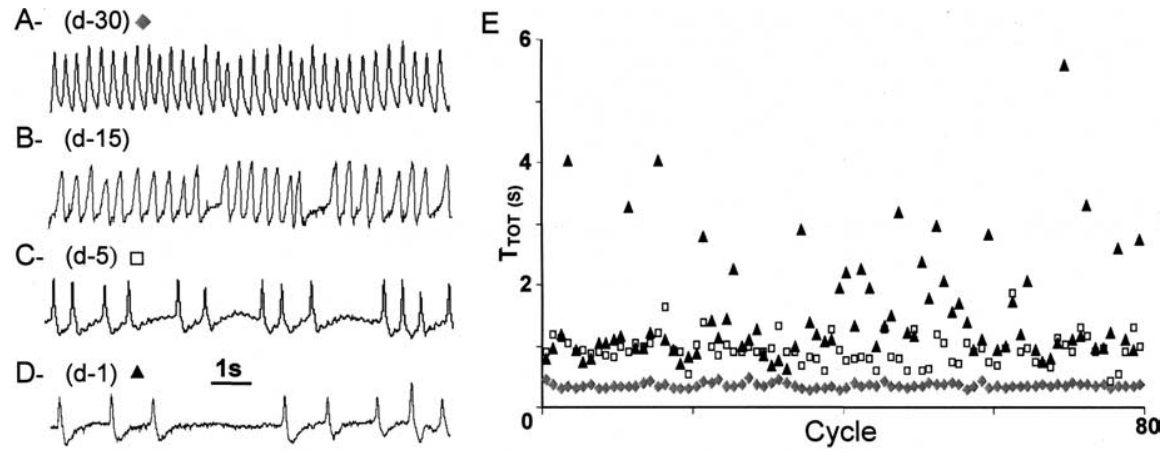

Figure 1. Pattern of breathing in Mecp2-/y adult mouse at different ages. A-D, The traces show typical plethysmographic recordings of breathing (inspiration upward) performed in the same unanesthetized, quiet Mecp2-/y adult mice at different ages: $30 \mathrm{~d}(\boldsymbol{A}), 45 \mathrm{~d}(\boldsymbol{B}), 55 \mathrm{~d}(\boldsymbol{C})$, and $59 \mathrm{~d}(\boldsymbol{D})$. This animal died at $60 \mathrm{~d}$ of age; (d-30), (d-15), (d-5), and (d-1) refer to the number of days before death. $\boldsymbol{E}$, Sequential plot of cycle period values ( $T_{\text {Тот }}$ in seconds) of 80 consecutive respiratory cycles recorded in the unanesthetized Mecp2-/y mouse shown in $\boldsymbol{A}-\boldsymbol{D}$ at $30 \mathrm{~d}$ (lozenges), $5 \mathrm{~d}$ (open squares), and $1 \mathrm{~d}$ (triangles) before death.

potential of $+650 \mathrm{mV}$ against the $\mathrm{Ag} / \mathrm{AgCl}$ reference electrode of the electrochemical detector (model 105; Precision Instruments, Sarasota, $\mathrm{FL}$ ), and the sensitivity of the detection was set to $0.05 \mathrm{nA} \mathrm{V}^{-1}$. The compound concentrations were also measured in $1 \mu \mathrm{l}$ standard samples injected by a Biotek 565 Autosampler (UVK Laboratory) into an hypersil ODS Column $(200 \times 3 \mathrm{~mm} ; 3 \mu \mathrm{m}$; Phymep, Paris, France $)$ in which the polar mobile phase (in mM: 120 citric acid, 430 potassium hydrogenophosphate, 4.2 heptane sulfonic acid, 1.7 EDTA, and 10\% methanol in $\mathrm{H}_{2} \mathrm{O}$ ) was delivered at a rate of $0.2 \mathrm{ml} \mathrm{min}^{-1}$. The endogenous concentrations were expressed in nanomol per liter per milligram of brain sample.

Immunohistofluorescence. One- and 2-month-old mice were anesthetized with a lethal pentobarbitone injection $\left(300 \mathrm{mg} \mathrm{kg}^{-1}\right.$, i.p.) and transcardially perfused (chilled saline for $1 \mathrm{~min}$ followed by $0.1 \mathrm{M}$ PBS containing 4\% paraformaldehyde for $10 \mathrm{~min}$ ). Brains were postfixed for $5 \mathrm{~h}$ and placed overnight in PBS containing 20\% sucrose. For neonatal mice, brains were dissected and fixed by immersion for $12 \mathrm{~h}$ and placed overnight in PBS containing 20\% sucrose. Medullary coronal sections were cut on a cryostat $(20 \mu \mathrm{m})$, and one of every successive five slices was arranged serially on a slide. Sections were permeabilized $(0.15 \%$ Triton $\mathrm{X}-100$ ), blocked with 7\% normal goat serum, and incubated overnight at $4^{\circ} \mathrm{C}$ with primary antibody in PBS containing $3.5 \%$ serum and $0.15 \%$ Triton X-100. Sections were washed, incubated with secondary antibody in PBS containing 3.5\% serum and 5\% Triton X-100, and rewashed. The sections were subsequently mounted in ProLong Antifade (Molecular Devices, Eugene, OR). Tyrosine hydroxylase (TH) (1:1000; Institut J. Boy, Reims, France), 5-HT (1:1000; Sigma-Aldrich), and choline acetyl transferase (ChAT) (1:500; Chemicon, Temecula, CA) were probed with affinity-purified rabbit polyclonal antibodies. Goat anti-rabbit (Alexa 488; 1:200; Molecular Devices) was used as a secondary antibody. Each $\mathrm{TH}, 5-\mathrm{HT}$, and ChAT antibody was applied to only one of every five successive sections. The nuclei of immunolabeled cell bodies were counted with an Olympus (Tokyo, Japan) BX50 microscope equipped with a high-resolution digital camera (excitation, $488 \mathrm{~nm}$; detection, 515-540 nm bandpass filter). The number of TH neurons in the ventral $\mathrm{A} 1 / \mathrm{C} 1$ and dorsal A2/C2 groups, 5-HT-positive neurons in the median $\mathrm{B} 1-\mathrm{B} 2$, and lateral B3 5-HT groups and ChAT-positive neurons in the X and XII motor nuclei were determined in every immunolabeled section. For neonatal and 1-month-old mice, only the TH analysis was performed. The number of TH neurons is expressed as the mean \pm SE.

Statistical analysis. The data were analyzed with SPSS software (SPSS Science, Erkrath, Germany). For all tests, the statistical significance was taken at $p \leq 0.05$.

Variability of respiratory cycle period. To analyze the variability of the respiratory cycle period, we used several statistical tests depending on experimental conditions. For in vivo data, we used the one-tailed Moses rank-like test for scale differences (Siegel and Catellan, 1989) to compare the dispersion of $T_{\mathrm{TOT}}$ or $V_{\mathrm{T}}$ distributions (100 respiratory cycles) between paired animals (one Mecp2-/y mouse and its wt littermate re- corded on the same day) or between paired conditions (unanesthetized and anesthetized Mecp2-/y mouse). Then, the $p$ values obtained for each pair were combined by the Edgington procedure as described by Krauth (1990). Briefly, if $k$-independent comparisons give $k$ the $p$ values, respectively, $p_{1}, p_{2} \ldots p_{\mathrm{k}}$, the $p$ value for the combined test, $p_{\mathrm{T}}$, is calculated according to the equation: $p_{\mathrm{T}}=s^{\mathrm{k}} / k$ !, in which $s=p_{1}$ $+p_{2}+\ldots+p_{\mathrm{k}}$. The $p_{\mathrm{T}}$ value gives the probability that the variability was higher in one condition than the other. For in vitro data, we calculated both the coefficient of variation $(\mathrm{CVd})$ and the irregularity score (IS) of cycle period of VRG bursts produced in slice preparations. The $\mathrm{CVd}$ was defined here as the ratio between of the SD and the mean cycle period measured during 80 successive respiratory cycles ( $\mathrm{Vi}$ emari et al., 2004); mean CVd values are given in the text but are not statistically compared because we lack adequate tests. The IS was defined for each cycle by applying the formula for consecutive cycle period values, $100 \times \operatorname{ABS}\left(P_{\mathrm{n}}-P_{\mathrm{n}-1}\right) / P_{\mathrm{n}-1}$, with $P$ being the period of the $n$th respiratory cycle (Telgkamp et al., 2002); mean IS values for wt and Mecp2-/y mice were compared by Student's $t$ test. In addition, we also used the one-tailed Moses rank-like test for scale differences followed by the Edgington procedure to compare the distribution of respiratory cycle period between paired wt-Mecp2-/y slices (mice from the same litter).

Other data. For biochemical data, results are given as medians \pm quartile deviation (i.e., half of the difference between the 75 th and the 25 th percentile), and the statistical differences between the wt and Mecp2-/y mice were analyzed by the nonparametric Mann-Whitney $U$ test. For pharmacological data, the frequency changes induced by ACSF containing NE were analyzed by one-way ANOVA (experimental conditions: control and NE application) for repeated measures in the same subjects, followed by Tukey's tests as multiple-comparisons procedure. The effect of NE application on the IS was analyzed by a two-way ANOVA for repeated measurements in the same subjects with only one repeated factor (experimental conditions), with the factors strain (wt or Mecp2-/y mice) and experimental condition (control, NE application and recovery). This was followed by Tukey's tests as a multiple-comparisons procedure.

\section{Results}

\section{Altered breathing pattern in adult Mecp2-/y mice}

Plethysmography recordings were performed in 25 unrestrained Mecp2-/y mice. Fifteen young mice were recorded at least once before 1 month of age and thereafter were killed for other analyses. Additionally, 10 adult mice were recorded several times between 1 and 2 months of age.

None of the 15 young Mecp2-/y mice presented severe breathing disturbances when studied at postnatal day 4 (P4) to P5 ( $n=$ $2), \mathrm{P} 10-\mathrm{P} 14(n=8)$, and P21 $(n=5)$. Most of them had normal breathing patterns with stable cycle periods, although short apneas lasting 1-2 s were occasionally observed in one of the eight P10-P14 mice and in three of the five P21 mice (median, three apneas during $15 \mathrm{~min}$ recording sessions; range, 2-5). These apneic episodes were interleaved with respiratory cycles of variable period.

At 4 weeks of age, the 10 adult Mecp2-/y mice also had breathing patterns that were not obviously different from that of their wt littermates (Figs. 1A, 2A). However, in the following weeks, they began to develop breathing difficulties that worsened until death (Fig. $1 B-D$ ). The appearance and progression of these breathing disturbances were highly variable from individual to individual. As reported previously (Guy et al., 2001), Mecp2-/y mice fail to thrive, and their lifespan is typically short (averaging 


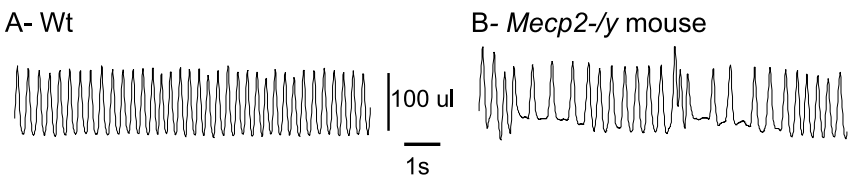

C- Mecp2-/y mouse
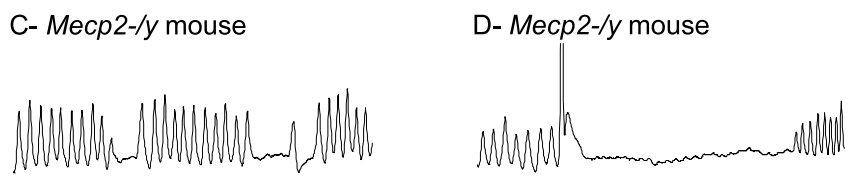

E-Wt

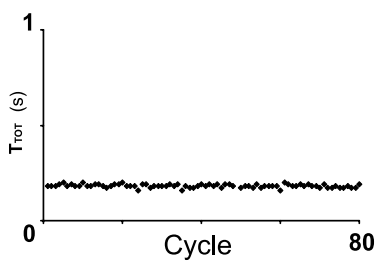

F- Mecp2-/y mouse

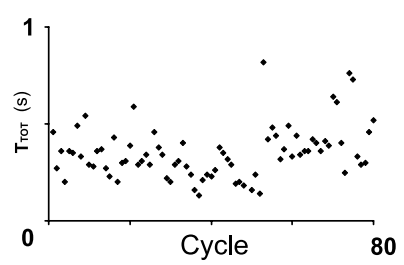

Figure 2. Breathing disturbances in Mecp2-/y adult mice. $\boldsymbol{A}-\boldsymbol{D}$, Plethysmographic recordings of breathing (inspiration upward) at $\sim 6$ weeks of age in unanesthetized, quiet wt $(A)$, and Mecp2-/y (B-D) adult mice. Mecp2-/y mice show a mixture of slow and fast respiratory rhythm $(\boldsymbol{B})$ and periods of short-lasting $(\boldsymbol{C})$ and long-lasting $(\boldsymbol{D})$ apneas. $\boldsymbol{E}, \boldsymbol{F}$, Sequential plot of $T_{\text {Tот }}$ values (in seconds) of 80 consecutive respiratory cycles recorded in wt $(\boldsymbol{E})$ and Mecp2-/y $(\boldsymbol{F})$ adult mice reveal that $T_{\text {Tот }}$ values are regular in the wt mouse but scattered in the Mecp2-/y mouse.

$54 \mathrm{~d}$ ), although some animals survive until 3 months of age. In our sample, the adult Mecp2-/y mice had a significantly reduced body weight ( $23 \pm 1$ and $15 \pm 2 \mathrm{~g}$ for wt and Mecp2-/y mice) and a shortened lifespan. Eight Mecp2-/y mice died before 2 months of age (median, $54 \mathrm{~d}$; range, 32-60 d), two survived until 67 and $89 \mathrm{~d}$ and all presented breathing disturbances that developed during the studied period. Data from recordings taken $\sim 15 \mathrm{~d}$ before death (i.e., typically $\sim 6$ weeks of age) indicated that the mean breathing frequency was not significantly different in wt and Mecp2-/y mice ( $3.25 \pm 0.28$ vs $2.95 \pm 0.50 \mathrm{~Hz}$, respectively), but Mecp2-/y mice displayed alternating periods of fast and slow respiratory frequencies (Fig. $2 B$ ) and apneas of variable duration (Figs. $1 B, 2 C, D$ ) (median, six apneas lasting $>1 \mathrm{~s}$ during $15 \mathrm{~min}$ recording sessions; range, 3-25). Indeed, the respiratory cycle period was more variable in Mecp2-/y than wt mice (Fig. 2E,F). In Mecp2-/y mice, the apneas were sometimes preceded by an increase in the breathing frequency or by a large inspiration (Fig. $2 D$ ). However, this was not always the case (Fig. $1 B$ ); thus, the occurrence of apneas was therefore unpredictable. In addition, a given Mecp2-/y mouse that displayed breathing disturbances during two to three consecutive recording sessions of $15 \mathrm{~min}$ might transiently show an apparently normal breathing during the next recording session, only to return to disordered breathing in subsequent recordings. One week later (i.e., $\sim 7 \mathrm{~d}$ before death), breathing disturbances were nearly unremitting and very severe (Fig. $1 C, D)$, with a significantly reduced mean breathing frequency $(3.33 \pm 0.23$ vs $1.55 \pm 0.38 \mathrm{~Hz}$ for wt and Mecp2-/y mice, respectively) and very frequent long-lasting apneas (median, 10 apneas lasting $>1$ s during 15 min recording sessions; range, 5-75).

The variability of the lifespan as well as the onset and progression of breathing disturbances in Mecp2-/y mice precluded a statistical study on the whole sample of $10 \mathrm{Mecp} 2-/ \mathrm{y}$ mice. For this reason, we focused our statistical analysis in-
A1- Wt

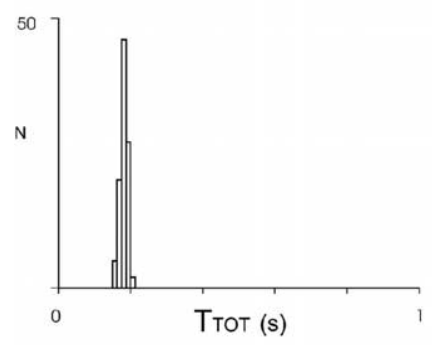

B1- Wt

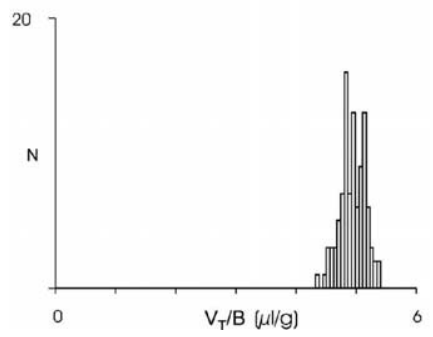

A2- Mecp2-/y mouse

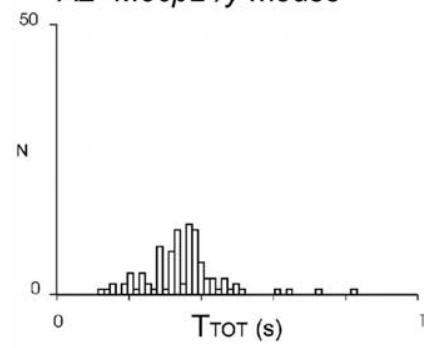

B2- Mecp2-/y mouse

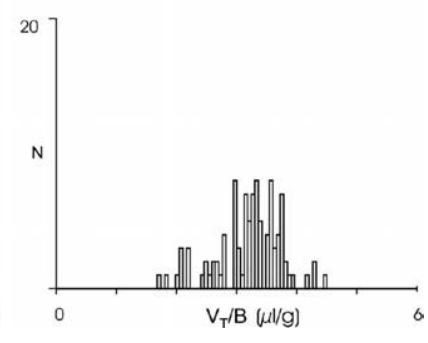

Figure 3. Comparison of breathing parameters in wt and Mecp2-/y adult mice. Distribution of $T_{\text {Tот }}$ and $V_{\mathrm{T}} / B$ values recorded in unanesthetized paired wt and $M e c p 2-/ y$ mice from the same litter (recording performed the same day). Frequency histograms represent the number of occurrences (ordinate) of $T_{\text {TOT }}\left(\boldsymbol{A} 1, \boldsymbol{A} \mathbf{2}\right.$, abscissa) and $V_{\mathrm{T}} / \boldsymbol{B}(\boldsymbol{B} \mathbf{1}, \boldsymbol{B} \mathbf{2}$, abscissa) values on 100 consecutive respiratory cycles during quiet breathing in the wt mouse $(\boldsymbol{A 1}, \boldsymbol{B 1})$ and the Mecp2-/y mouse $(\boldsymbol{A 2}, \boldsymbol{B} \mathbf{2})$ from one pair of littermates.

stead on five pairs of Mecp2-/y and wt littermates, the breathing patterns of which were recorded on the same day at least once every week from 1 month of age up to the spontaneous death of the Mecp2-/y mouse. Specifically, we compared the stability of $V_{\mathrm{T}}$ (divided by the body weight, $V_{\mathrm{T}} / B$ ) and $T_{\mathrm{TOT}}$ in these mice. Although $T_{\text {Tот }}$ varied from individual to individual, it was very regular in a given wt mouse (Fig. $2 A, E$ ) but very irregular in a given Mecp2-/y mouse (Fig. $2 B, F$ ). As illustrated in the frequency histograms (Fig. 3), the distribution of the $V_{\mathrm{T}} / B$ and $T_{\mathrm{TOT}}$ values was less dispersed in wt than in Mecp2-/y mice. At $\sim 15$ d before the Mecp2-/y death, statistical analysis of the raw values with the Moses rank-like test for scale differences revealed a significant difference between the members of each pair of $T_{\mathrm{TOT}}$ and $V_{\mathrm{T}} / B$ values. The Edgington procedure, which allows generalization of the statistical analysis to the tested populations, confirmed a significant difference between Mecp2-/y and wt mouse populations as a whole.

Thus, Mecp2 deficiency significantly alters the breathing patterns in adult mice, inducing a highly variable cycle period. Interestingly, Mecp2-/y mice were, however, capable of generating regular breathing in the presence of light anesthesia. This effect was analyzed in five Mecp2-/y adult mice that displayed breathing disturbances (Fig. 4A1). Ten minutes after anesthesia onset, breathing activity became regular and stable with no apneas (Fig. $4 A 2)$. The distributions of $T_{\mathrm{TOT}}$ and $V_{\mathrm{T}}$ were significantly different in unanesthetized (Fig. $4 B 1, C 1$ ) and anesthetized conditions (Fig. 4B2,C2), and the significance was confirmed for the population with the Edgington procedure.

\section{Altered in vitro respiratory rhythmogenesis in young Mecp2-/y mice}

In young mice, the numerous peripheral inputs that converge on the respiratory rhythm generating (RRG) network and regulate its activity in vivo may have masked or compensated for some central respiratory deficits. Therefore, we isolated a critical por- 
A1- Mecp2-/y Unanesthetized

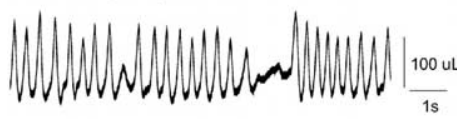

B1- Mecp2-/y Unanesthetized

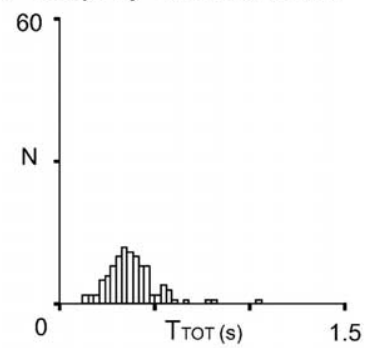

C1- Mecp2-/y Unanesthetized

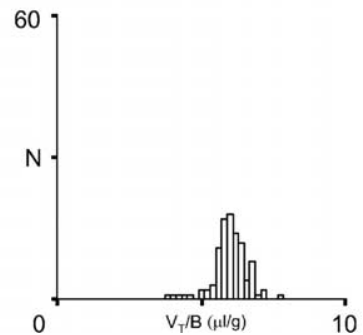

10

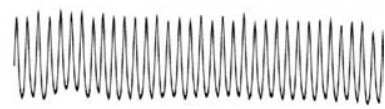

B2- Mecp2-/y Anesthetized

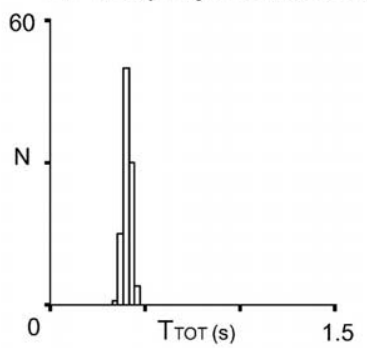

C2- Mecp2-/y Anesthetized

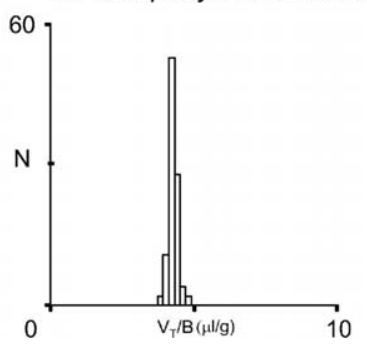

A2- Mecp2-/y Anesthetized

Figure 4. Slight anesthesia stabilizes the breathing parameters of Mecp2-/y adult mice. $\boldsymbol{A}$, Plethysmographic recordings obtained from the same Mecp2-/y mouse when unanesthetized (A1) and anesthetized (A2). B, C, Frequency histograms present the number of occurrences of $T_{\mathrm{TOT}}(\boldsymbol{B} 1, \boldsymbol{B} 2)$ and $V_{\mathrm{T}} / B(\boldsymbol{C} 1, \boldsymbol{C} 2)$ values on 100 consecutive respiratory cycles during awake $(\boldsymbol{B} 1$, C1) and anesthetized (B2, $\mathbf{C})$ conditions in the same Mecp2-/y mouse.

tion of the RRG network from these peripheral inputs by using a transverse brainstem slice preparation. This slice contains neurons of the VRG (Fig. 5A) that are thought to form a network that generates the basic respiratory rhythm. Spontaneously generated bursts of population activity recorded from this region in vitro have been shown to correspond to in vivo inspiratory activity and are thus termed fictive inspiration (Telgkamp and Ramirez, 1999).

\section{Abnormal respiratory rhythm in brainstem slices from Mecp2-/y mice}

The in vitro generation of rhythmic VRG bursts was compared between slices from $14 \mathrm{wt}$ and 9 Mecp2-/y mice (P14-P21) (i.e., an age when plethysmographic recordings did not yet reveal drastic breathing alterations in vivo). Neither the shape of the VRG burst, not the mean duration of VRG bursts $(0.42 \pm 0.02$ and $0.43 \pm 0.03 \mathrm{~s}$ for wt and Mecp $2-/ \mathrm{y}$ mice $)$, nor their mean frequency $(0.22 \pm 0.02$ and $0.29 \pm 0.05 \mathrm{~Hz}$ for wt and Mecp2-/y mice) was statistically different. However, the cycle period of VRG bursts was highly irregular in Mecp2-/y slices when compared with wt slices (Fig. 5B1,B2) as illustrated by sequential cycle period scatter plots (Fig. $5 C 1, C 2$ ). The irregularity of the cycle period was quantified by calculating both the CVd and the IS. Both values were approximately twofold higher in Mecp2-/y (0.56 \pm 0.07 and $54 \pm 6$ for CVd and IS, respectively) than in wt slices $(0.27 \pm 0.03$ and $28 \pm 2$ for CVd and IS, respectively). In addition, in five paired slices from wt and Mecp2-/y littermates, the Moses rank-like test for scale differences confirmed that the distribution of the VRG cycle period was less dispersed in wt (Fig. 5D1) than in Mecp2-/y slices (Fig. 5D2), and the Edgington procedure revealed a significant difference between the two populations.

\section{NE stabilizes the respiratory rhythm in brainstem slices of} Mecp2-/y mice

Because NE is known to play a role in respiratory rhythm regulation (Hilaire et al., 2004; Viemari et al., 2004, 2005), we examined whether the irregularity of the cycle period in slices from Mecp2-/y mice may result from a disruption of noradrenergic mechanisms. Exogenously applied NE significantly increased the VRG burst frequency in both wt and Mecp2-/y slices by $79 \pm 17 \%$ $(n=5)$ (Fig. $6 A)$ and $123 \pm 53 \%(n=5)$ (Fig. $6 B)$, respectively. In the presence of NE, the mean VRG burst frequency did not differ between wt and Mecp2-/y slices (0.39 \pm 0.01 and $0.49 \pm$ $0.11 \mathrm{~Hz}$, respectively). Moreover, NE application eliminated the rhythm irregularity in all examined slices from Mecp2-/y mice (Fig. 6 B2,C2,C3), halving the CVd and IS values $(0.29 \pm 0.1$ and $31 \pm 1, n=5$, respectively). In contrast, NE application in slices from wt mice had no effect on CVd and IS values. Thus, in the presence of NE, slices from wt and Mecp2-/y mice produced rhythmic VRG bursts with a statistically similar frequency and regularity. Furthermore, the cycle period of VRG bursts remained regular in Mecp2-/y mice for at least 5-10 min after washout of NE $(0.33 \pm 0.04$ and $33 \pm 3, n=3$, for CVd and IS, respectively), whereas the VRG burst frequency returned to control values $(0.18 \pm 0.03 \mathrm{~Hz}, n=3)$.

Thus, these in vitro results in slices from wt and Mecp2-/y mice reveal that Mecp2 deficiency alters the cycle period stability and that application of exogenous NE restores the cycle period stability.

\section{NE alterations in Mecp2-/y mice}

We examined whether Mecp2-/y adult and young mice have a deficiency in NE systems that could contribute to their breathing disturbances.

\section{Two-month-old mice}

We assessed the endogenous concentrations of NE, 5-HT, 5HIAA, and dopamine using HPLC analysis of the medulla, pons, and forebrain of 2-month-old wt $(n=12)$ and Mecp2-/y mice $(n=7)$, which had severe respiratory problems similar to those illustrated in Figure 1, $C$ and D. In the medulla, NE and 5-HT concentrations were significantly lower in Mecp2-/y than in wt mice $(7.0 \pm 4.3$ vs $13.5 \pm 2.3 \mathrm{~nm} / \mathrm{mg}$ for $\mathrm{NE}$ and $6.4 \pm 2.6 \mathrm{vs}$ $10.1 \pm 1.6 \mathrm{~nm} / \mathrm{mg}$ for $5-\mathrm{HT}$ ) (see Table 1). Despite the decreased 5 -HT concentration in Mecp2-/y mice, the 5HIAA concentrations were not significantly different in wt and Mecp2-/y mice ( $8.7 \pm 0.8$ vs $8.5 \pm 0.7 \mathrm{~nm} / \mathrm{mg}$, respectively), leading to a significantly increased 5HIAA/5-HT ratio in Mecp2-/y mice. In contrast, the dopamine concentration was not different. In the pons and forebrain, NE, dopamine, and 5-HT concentrations did not differ between wt and Mecp2-/y mice (data not shown).

We immunolabeled medullary $\mathrm{TH}$ neurons in five paired $\mathrm{wt}$ and Mecp2-/y littermates at 2 months of age. TH neurons were found in the ventral A1/C1 (Fig. 7D) and dorsal A2/C2 (Fig. $\left.7 B, B^{\prime}\right)$ catecholaminergic groups of wt and Mecp2-/y mice. Neuron counts revealed a significantly reduced number of $\mathrm{TH}$ neurons in Mecp2-/y mice. The number of TH neurons was significantly reduced in the A1/C1 group of Mecp2-/y mice (302 \pm 70 and $211 \pm 48$ neurons for wt and Mecp2-/y mice, respectively). In the entire A2/C2 group (from $2 \mathrm{~mm}$ caudal to $2 \mathrm{~mm}$ rostral to the obex), the number of TH neurons was also significantly reduced in Mecp2-/y mice (325 \pm 19 and $204 \pm 9$ TH neurons for wt and Mecp2-/y mice, respectively). The number of immunolabeled neurons expressing 5-HT in the median B1-B2 groups and the lateral B3 group was not significantly different between wt and 
Mecp2-/y mice $(244 \pm 26$ and $228 \pm 26$, respectively) (Fig. 7C). The number of immunolabeled neurons expressing ChAT in the $\mathrm{X}$ and XII motor nuclei (Fig. 7A) was not significantly different between wt and Mecp2-/y mice (235 \pm 62 and $213 \pm 90$ in the $\mathrm{X}$ motor nucleus and $280 \pm 63$ and $295 \pm 79$ in the XII motor nucleus, for wt and Mecp2-/y mice, respectively).

One-month-old mice and neonatal mice We assessed the endogenous concentrations of endogenous bioamines by HPLC analysis of eight wt and seven Mecp2-/y mice at 1 month of age. At this early age, these Mecp2-/y mice presented no $(n=2)$ or only minor alterations $(n=5)$ of the respiratory rhythm stability and few apneas (three to six apneas lasting $>1$ s during $15 \mathrm{~min}$ recording sessions). However, NE concentrations were already significantly lower in Mecp2-/y mice than in wt mice $(40 \%)$. This reduction was observed in all five studied Mecp2-/y mice (i.e., three with slight breathing alterations and two with unaltered breathing). In contrast, medullary 5-HT and medullary dopamine concentrations were normal in all examined mice (Table 1). At 1 month of age, neuron counts in two paired wt and Mecp2-/y young littermates revealed that the number of $\mathrm{TH}$ neurons in the dorsal $\mathrm{A} 2 / \mathrm{C} 2$ area of the Mecp2-/y mice was $\sim 60 \%$ of the wt values ( 345 vs 185 and 393 vs 269 neurons for the two pairs of wt and Mecp2-/y mice, respectively). In the ventral A1/C1 area, the Mecp2-/y cell count was low in the Mecp2-/y mouse from one pair (236 vs 144) but within the same range in the Mecp2-/y mouse and the wt mouse from the other pair (280 vs 260).

Finally, we counted the number of $\mathrm{TH}$ neurons in the medulla of three paired wt and Mecp2-/y neonates (3 d of age) that displayed a normal breathing. Although a larger number of $\mathrm{TH}$ neurons was found in neonates than in adults, no significant differences were observed between wt and Mecp2-/y neonates (A1/C1 neurons, $414 \pm 63$ vs $382 \pm 13$ neurons for wt and Mecp2-/y neonates; A2/C2 neurons, $485 \pm 61$ vs $458 \pm 27$ neurons for wt and Mecp2-/y neonates).

These findings suggest that Mecp2 deficiency induces a specific reduction of the medullary NE contents in adult mice concomitant with a reduction of the number of medullary TH neurons that occurs postnatally around the first month of age and precedes the occurrence of drastic breathing alterations.

\section{Discussion}

Here, we show that Mecp2 deficiency in mice leads to slow, irregular respiratory rhythmic activity, a reduction in medullary NE and 5-HT content, and a decrease in the number of medullary $\mathrm{TH}$ neurons. We hypothesize that breathing disturbances in
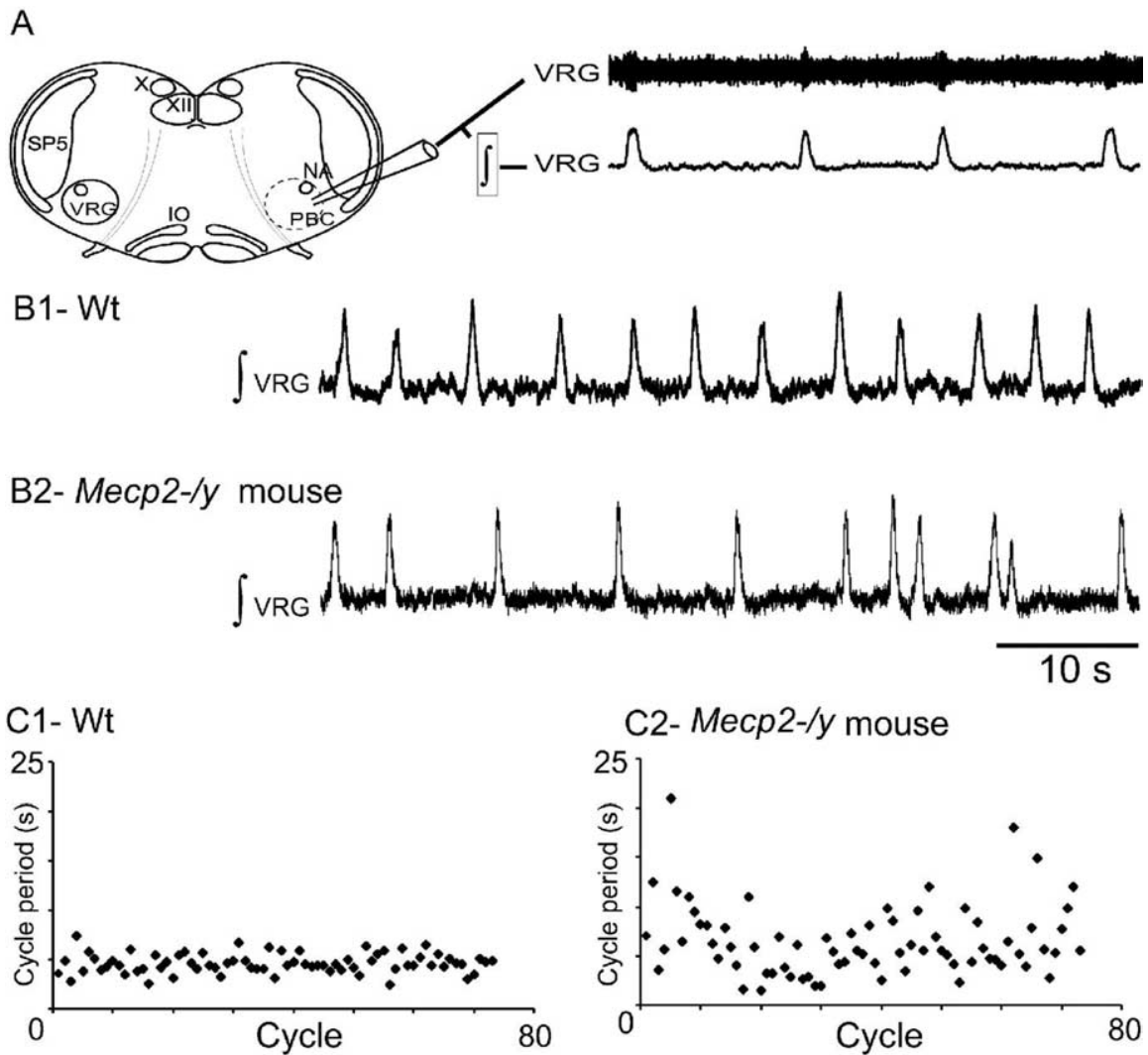

C2- Mecp2-/y mouse

D1- Wt
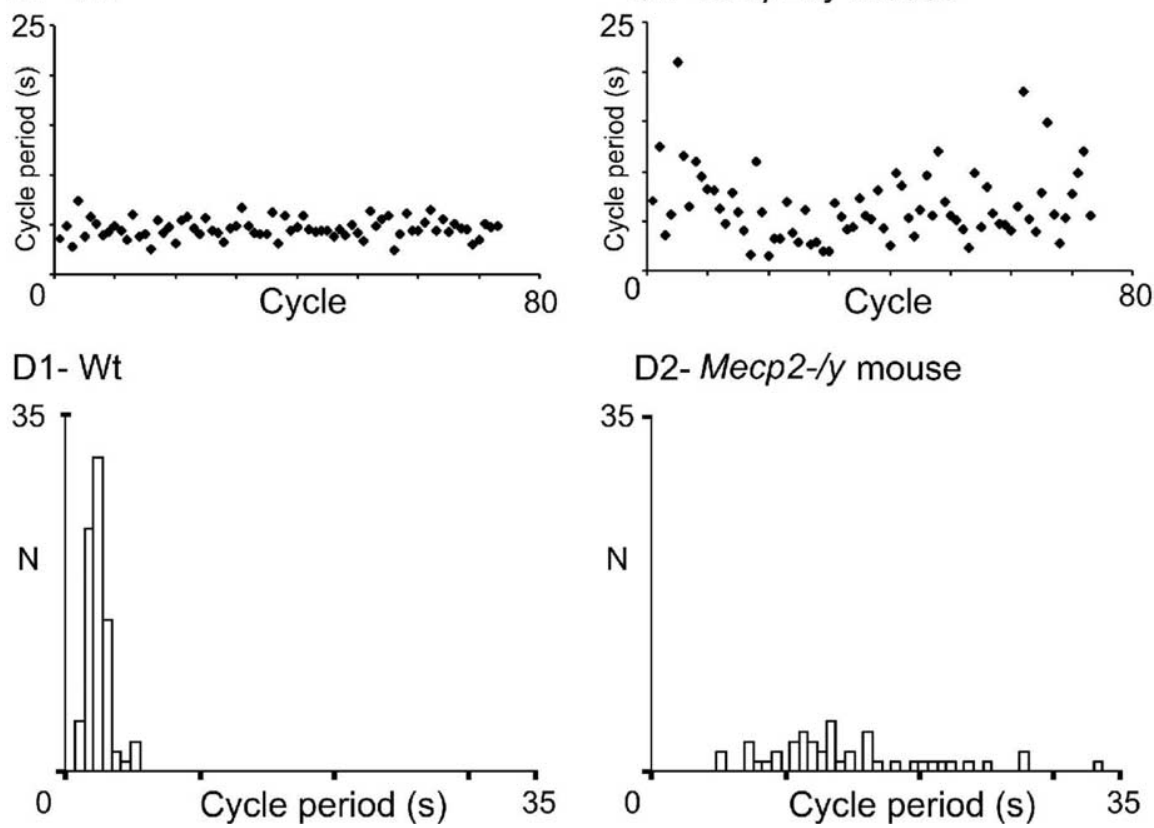

D2- Mecp2-/y mouse

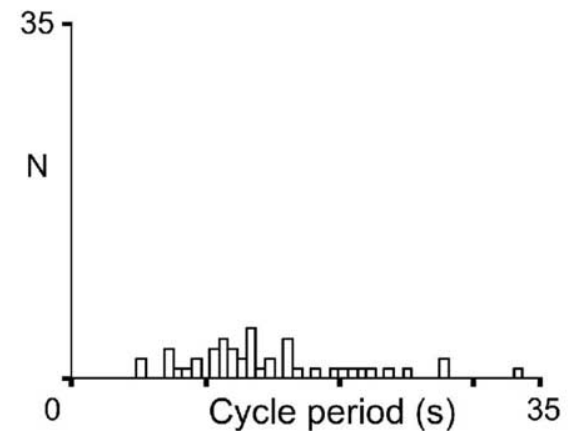

Figure 5. Central respiratory rhythm is disturbed in young Mecp2-/y mice. $\boldsymbol{A}$, Schematic of a transverse brainstem slice that spontaneously generates respiratory rhythmic activity. Top trace, Extracellular population activity recorded from the VRG. Bottom trace, Integrated activity obtained from the extracellular population activity. X, Vagus nuclei; XII, hypoglossal nuclei; PBC, preBötzinger complex area; SP5, spinal trigeminal nucleus; VRG, ventral respiratory group; 10, inferior olive. B1, Integrated regular frequency histograms (D) of cycle period (s) obtained for 80 consecutive VRG bursts recorded in brainstem slices from wt $(\boldsymbol{C 1}, \mathbf{D 1})$ and Mecp2-/y $(\mathbf{C}, \mathbf{D} 2)$ mice. Note the cycle period variability in the Mecp2-/y mouse.

Mecp2-/y mice, and possibly also in Rett patients, involve a disturbance in the bioaminergic modulation of the respiratory system. The neurological disorders associated with Rett syndrome appear after 6-18 months of age and are caused by mutations in the MECP2 gene (Van den Veyver and Zoghbi, 2000; Ravn et al., 2005). However, it remains unknown how a mutation in the MECP2 gene leads to the observed neurological phenotype. Among the hypotheses proposed to explain the mechanisms that lead to the neurological symptoms of Rett syndrome, several suggest an alteration in bioaminergic function. However, existing evidence is not conclusive (Nomura et al., 1985; Zoghbi et al., 1985, 1989; Riederer et al., 1986; Lekman et al., 1990; Nielsen et al., 1990; Segawa, 1997; Dunn, 2001). 
A1- Wt

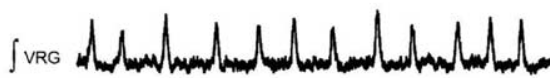

B1- Mecp2-/y mouse

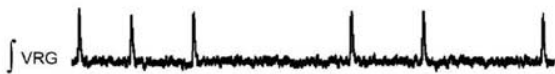

$\mathrm{A} 2-\mathrm{Wt}+\mathrm{NE}$
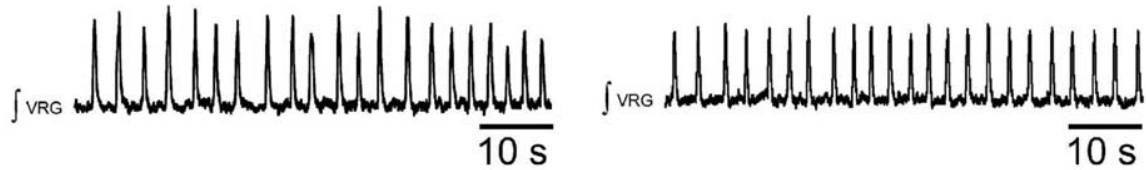
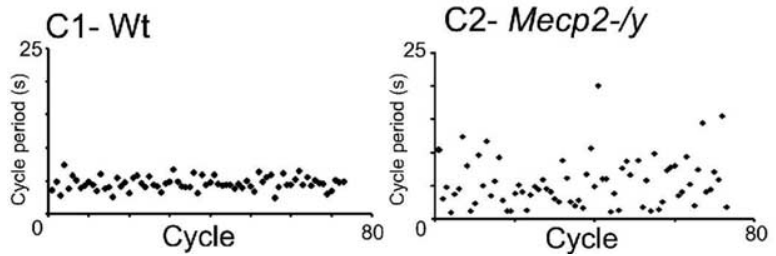

C2- Mecp2-/y

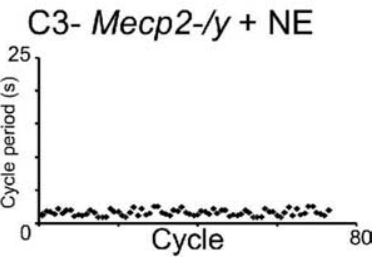

Figure 6. Effect of NE application on VRG rhythm produced in slices from wt and Mecp2-/y mice. A1, Integrated population activity from a wt slice preparation before application of NE. A2, In the same animal, exogenous application of NE (20 $\mu \mathrm{M})$ increases the respiratory rhythmic frequency. $\boldsymbol{B 1}$, Integrated population activity from a Mecp2-/y mouse before application of NE. B2, Exogenously applied NE $(20 \mu \mathrm{m})$ significantly increases the regularity and frequency of respiratory rhythmic activity. $\boldsymbol{C}$, Examples of sequential cycle period histograms for a wt (C1), a Mecp2-/y mouse before NE application (C2), and the same Mecp2-/y mouse in the presence of NE (C3). Each histogram represents cycle period values (ordinate; seconds) calculated for 80 consecutive cycles (abscissa). Note that the cycles period values become more regular after adding $\mathrm{NE}$.

Table 1. Mecp2 deficiency alters NE systems in the medulla

\begin{tabular}{lrcl}
\hline & wt & $p$ & Mecp2-/y \\
\hline 2 months & & & \\
NE & $13.5 \pm 2.3(n=12)$ & $*$ & $7.0 \pm 4.3(n=7)$ \\
$5-H T$ & $10.1 \pm 1.6(n=12)$ & $*$ & $6.4 \pm 2.6(n=7)$ \\
DA & $0.6 \pm 0.2(n=12)$ & ns & $0.5 \pm 0.2(n=7)$ \\
1 month & & & \\
NE & $15.0 \pm 1.6(n=6)$ & $*$ & $9.2 \pm 0.8(n=5)$ \\
$5-H T$ & $10.9 \pm 1.8(n=6)$ & ns & $8.1 \pm 1.5(n=5)$ \\
DA & $0.8 \pm 0.2(n=6)$ & ns & $0.6 \pm 0.3(n=5)$ \\
\hline
\end{tabular}

The results are expressed as medians \pm quartile deviation in $\mathrm{nm} / \mathrm{mg}$. Asterisks and $\mathrm{ns}$ indicate significant and nonsignificant differences, respectively, between wt and Mecp2-/y mice of the same age. DA, Dopamine.

Our data suggest that Mecp2 deletion produced altered bioaminergic function of Mecp2-/y mice during the postnatal period. The time courses of these postnatal changes in bioaminergic function were diverse and differed for different portions of the bioaminergic system. In Mecp2-/y mice, an initial decrease in NE content at 1 month of age was followed by a secondary decrease in 5 -HT content at 2 months of age. These changes in NE and 5-HT content were specific to the medulla, whereas bioaminergic content in pons and forebrain remained normal. Our HPLC results confirm HPLC measurements performed in the whole brain of Mecp2-/y mice (Ide et al., 2005). Ide et al. (2005) found no bioaminergic alteration at birth in Mecp2-/y mice, and NE content tended to be reduced at P14. Significant reduction in NE content was measured at P28, and a significant reduction in 5-HT content was measured at P42 (Ide et al., 2005).

Our immunohistological approach shows that the number of TH neurons in Mecp2-/y mice was normal at birth. At 1 month of age, the number of $\mathrm{A} 2 / \mathrm{C} 2$ neurons was decreased, and at 2 months of age, the number of $\mathrm{A} 1 / \mathrm{C} 1$ as well as $\mathrm{A} 2 / \mathrm{C} 2$ neurons was decreased in Mecp2-/y mice. Although counts of TH neurons cannot discriminate between NE or epinephrine neurons located within $\mathrm{A} 1 / \mathrm{C} 1$ and A2/C2, HPLC measurements in Mecp2-/y mice indicate a reduction in NE content. The mechanisms through which Mecp2 deficiency results in a progressive neuronal death of $\mathrm{TH}$ neurons and/or a loss of the ability to synthesize NE remain unknown and were not addressed in the present study.

Here, we demonstrate that the decrease in 5-HT content measured with the HPLC approach was not accompanied by a change in the number of 5-HT neurons in the regions we studied. Our finding that the 5-HT content is decreased without a measurable change in the number of 5-HT neurons may be surprising. Our HPLC measurements and those performed by Ide et al. (2005) also revealed that the decrease in 5-HT concentration was not accompanied by a decreased 5HIAA concentration. We measured a significantly increased 5HIAA/5-HT ratio in Mecp2-/y mice that suggests changes in their 5-HT turnover. It is well established that raphe 5-HT neurons receive numerous inputs from most NE groups (Peyron et al., 1996). NE has been shown to regulate central 5-HT activity at the cell body level via stimulatory adrenoceptors (Svensson et al., 1975; Baraban and Aghajanian, 1980, 1981; Hopwood and Stamford, 2001; Bortolozzi and Artigas, 2003; Pudovkina et al., 2003; Linner et al., 2004). Based on these published observations, it can be assumed that NE inputs modulate 5-HT metabolism. One parsimonious explanation for the decreased 5-HT content is that the progressive loss of $\mathrm{A} 1 / \mathrm{C} 1$ and $\mathrm{A} 2 / \mathrm{C} 2$ neurons and the reduced NE content caused a progressive reduction of NE inputs to 5 -HT neurons. The initial effects on the NE modulatory system may not be sufficient to significantly affect the serotonergic system. The 5-HT effects may become only apparent at a time when the NE effects are fully manifested. A decreased activation of 5-HT neurons could indirectly alter 5-HT metabolism, thereby increasing the 5HIIAA/ 5-HT ratio.

Although the breathing of unanesthetized Mecp2-/y mice was normal at birth, obvious breathing irregularities were displayed at 1 month of age. These breathing irregularities were characterized by consecutive short and long respiratory cycles and recurrent respiratory arrests. NE deficits in Mecp2-/y mice may precede the measurable breathing disturbances in vivo. In vitro recordings in medullary P14-P21 slices obtained from Mecp2-/y mice revealed an increased variability in respiratory cycle duration that was abolished by exogenous NE application. Although pontine mechanisms contribute to normal breathing (St-John and Paton, 2004), compelling evidence suggests that the medulla is critical for generating normal breathing in vivo as well as respiratory-like rhythm in vitro. Lesioning of the pre-Bötzinger complex, a medullary region crucial for respiratory rhythmogenesis, severely disrupts breathing in vivo (Ramirez et al., 1998; Gray et al., 2001; Solomon 2002, 2003; Wenninger et al., 2004a,b) and fictive respiration in vitro (Onimaru et al., 1988; Viemari et al., 2003). Thus, the irregular respiratory rhythm measured in P14P21 Mecp2-/y slices suggests that central respiratory deficits in 
Mecp2-/y mice may arise early during postnatal development. The slices obtained from Mecp2-/y mice contain medullary nuclei that are strongly affected by the Mecp2 deficiency, the $\mathrm{A} 1 / \mathrm{C} 1$ and $\mathrm{A} 2 / \mathrm{C} 2$ regions. In wt mice, endogenous NE modulates the respiratory rhythm generator via A5 and A6 pontine neurons (Dawid-Milner et al., 2001; Viemari et al., 2003, 2004; Hilaire et al., 2004), as well as via $\mathrm{A} 1 / \mathrm{C} 1$ and $\mathrm{A} 2 / \mathrm{C} 2$ medullary neurons (Zanella et al., 2005). Although pontine NE content was normal in Mecp2-/y mice, the number of medullary TH neurons and the medullary NE content was significantly reduced. Because the number of $\mathrm{TH}$ neurons and the medullary content were reduced, we hypothesize that the variable respiratory rhythm in P14-P21 Mecp2-/y medullary slices is caused by the progressive loss of $\mathrm{A} 2 / \mathrm{C} 2 \mathrm{TH}$ neurons.

At this early age, plethysmography recordings obtained from Mecp2-/y mice showed an apparently normal breathing pattern in vivo, although some pups occasionally displayed apneic episodes interleaved with respiratory cycles of variable period. The finding that the in vitro respiratory network of Mecp2-/y mice shows irregularities, whereas the in vivo breathing of Mecp2-/y mice is apparently normal, which could be attributable to differences in the experimental approach. In the in vitro preparation, we measured the activity of the deafferented RRG network, which receives only medullary inputs from nervous structures preserved within the slice. In contrast, in the intact animal, we measured the breathing behavior in experimental conditions in which the RRG network received multiple inputs from many central (including neocortex, cerebellum, and pons) and peripheral (carotid bodies, lung afferents) structures. The breathing is also determined by various motor outputs (e.g., diaphragm, intercostal, and upper airway muscles). These inputs and outputs could potentially compensate for an early loss in medullary A2/C2 TH neurons, leading to an apparently normal breathing in young Mecp2-/y mice.

After the first month of age when both medullary NE concentration and number of $\mathrm{A} 2 / \mathrm{C} 2 \mathrm{TH}$ neurons were decreased in Mecp2-/y mice, these mice exhibited abnormal variability in breathing period. At $\sim 2$ months of age, the breathing deficits in Mecp2-/y mice worsen, being then characterized by very frequent long-lasting apneas and drastically reduced respiratory frequency. At this age, bioaminergic deficits in Mecp2-/y mice were not only limited to a reduction in the number of $\mathrm{A} 2 / \mathrm{C} 2 \mathrm{TH}$ neurons but included also abnormalities in the number of $\mathrm{A} 1 / \mathrm{C} 1$ TH neurons and the 5-HT medullary system. Early disturbances in respiratory frequency may originate, at least in part, from a decreased facilitation of the RRG network by the A1/C1 group. Neurons in the A1/C1 group continuously activate the RRG net- work via medullary $\alpha 2$-adrenoceptors (Zanella et al., 2005). The worsening of the breathing irregularities in Mecp2-/y mice could be explained by the disturbances in the 5-HT system. The 5-HT system in mammals is known to be critical for stable breathing and for normal respiratory rhythm generation (Morin et al., 1991; Lalley et al., 1995; Bou-Flores et al., 2000; Peña and Ramirez, 2002; Richter et al., 2003; Ladewig et al., 2004). Because of the importance of 5-HT for breathing, the decreased 5-HT levels that we observed in Mecp2-/y mice may contribute to the worsening of the respiratory disturbances. The worsening of the breathing disturbances in Mecp2-/y mice occurred at a time when the 5-HT system became disturbed. This suggests that the time course of NE and 5-HT deficiencies in Mecp2-/y mice could possibly explain the age-dependent worsening of respiratory deficits. Specifically, we hypothesize for Mecp2-/y mice the following time course of events: initial alterations occur in rhythmogenesis at 
P14-P21, a time when NE deficits first appear. Alterations in rhythmogenesis are followed by a variable breathing rhythm with recurrent apneas at 1 month of age at a time when both $\mathrm{NE}$ content and A2/C2 TH neurons are significantly affected. Finally, long-lasting apneas and a severe reduction in breathing frequency occur at 2 months of age, which coincides with the full manifestation of A2/C2, A1/C1, and 5-HT deficits.

Phox $2 a$ and Ret deficiencies affect the prenatal maturation of the RRG (Hilaire et al., 2004; Viemari et al., 2004, 2005). In contrast, the RRG network of Mecp2-/y mice undergoes normal maturation resulting in the production of normal respiratory movements at birth. Thereafter, as bioaminergic deficits progress during the postnatal period, the respiratory system of Mecp2-/y mice begins to dysfunction. However, the respiratory system of Mecp2-/y mice is still able to centrally generate a normal respiratory rhythm under certain circumstances: (1) adult Mecp2-/y mice with drastic respiratory alterations can spontaneously display transient periods of normal breathing; and (2) pentobarbital anesthesia restores normal breathing in all tested Mecp2-/y mice. It is worthwhile to note that human Rett patients may similarly have normal breathing periods during wakefulness and that their breathing can also improve during sleep. We do not know the mechanism by which pentobarbital anesthesia stabilizes and improves breathing in adult Mecp2-/y mice. It is known that this anesthetic depresses cerebral metabolism (Steen and Michenfelder, 1979) and resting respiration (Erhardt et al., 1984). Pentobarbital anesthesia is also affected by noradrenergic agents (Dessaigne et al., 1976; Ojima et al., 1995; Dalley et al., 1998), and other anesthetics have been shown to alter the activity and excitability of central NE neurons (Clement et al., 1998; Hirota and Kushikata, 2001) and to decrease mRNA levels of NE transporters (Hara et al., 2000).

To conclude, our results are consistent with the notion that Mecp2 deficiency in mice results in an alteration of the NE system and that NE deficits precede, and may contribute to, the development of respiratory deficits. Subsequent disturbances of other neuromodulators such as 5-HT may explain the delayed onset and worsening of the disturbed breathing phenotype.

\section{References}

Armstrong DD (1997) Review of Rett syndrome. J Neuropathol Exp Neurol 56:843-849.

Baraban JM, Aghajanian GK (1980) Suppression of firing activity of 5-HT neurons in the dorsal raphe by alpha-adrenoceptor antagonists. Neuropharmacology 19355-19363.

Baraban JM, Aghajanian GK (1981) Noradrenergic innervation of serotonergic neurons in the dorsal raphe: demonstration by electron microscopic autoradiography. Brain Res 204:1-11.

Bortolozzi A, Artigas F (2003) Control of 5-hydroxytryptamine release in the dorsal raphe nucleus by the noradrenergic system in rat brain. Role of $\alpha$-adrenoceptors. Neuropsychopharmacology 28:421-434.

Bou-Flores C, Lajard AM, Monteau R, De Maeyer E, Seif I, Lanoir J, Hilaire G (2000) Abnormal phrenic motoneuron activity and morphology in neonatal monoamine oxidase A-deficient transgenic mice: possible role of a serotonin excess. J Neurosci 20:4646-4656.

Burnet H, Bevengut M, Chakri F, Bou-Flores C, Coulon P, Gaytan S, Pasaro R, Hilaire G (2001) Altered respiratory activity and respiratory regulations in adult monoamine oxidase A-deficient mice. J Neurosci 21:5212-5221.

Clement CI, Keay KA, Bandler R (1998) Medullary catecholaminergic projections to the ventrolateral periaqueductal gray region activated by halothane anaesthesia. Neuroscience 86:1273-1284.

Cooper RA, Kerr AM, Amos PM (1998) Rett syndrome: critical examination of clinical features, serial EEG and video-monitoring in understanding and management. Eur J Paediatr Neurol 2:127-135.

Dalley JW, Parker CA, Wulfert E, Hudson AL, Nutt DJ (1998) Potentiation of barbiturate-induced alterations in presynaptic noradrenergic function in rat frontal cortex by imidazol(in)e alpha2-adrenoceptor agonists. Br J Pharmacol 125:441-446.

Dawid-Milner M, Lara J, Gonzales-Baron S, Spyer K (2001) Respiratory effect of stimulation of cell bodies of the A5 region in the anaesthetised rat. Pflügers Arch 441:434-443.

Dessaigne S, Scotto AM, Mercier J (1976) The effect of previous administration of adrenaline or isoprenaline on the activity of several hypnotics in mice. C R Seances Soc Biol Fil 170:1074-1080.

Dunn HG (2001) Neurons and neuronal systems involved in the pathophysiologies of Rett syndrome. Brain Dev 23 [Suppl 1]:S99-S100.

Dunn HG, MacLeod PM (2001) Rett syndrome: review of biological abnormalities. Can J Neurol Sci 28:16-29.

Elian M, Rudolf ND (1991) EEG and respiration in Rett syndrome. Acta Neurol Scand 83:123-128.

Erhardt W, Hebestedt A, Aschenbrenner G, Pichotka B, Blumel G (1984) A comparative study with various anesthetics in mice (pentobarbitone, ketamine-xylazine, carfentanyl-etomidate). Res Exp Med (Berl) 184:159-169.

Gray PA, Janczewski WA, Mellen N, McCrimmon DR, Feldman JL (2001) Normal breathing requires preBotzinger complex neurokinin-1 receptorexpressing neurons. Nat Neurosci 4:927-930.

Guy J, Hendrich B, Holmes M, Martin JE, Bird A (2001) A mouse Mecp2null mutation causes neurological symptoms that mimic Rett syndrome. Nat Genet 27:322-326.

Hagberg B, Aicardi J, Dias K, Ramos O (1983) A progressive syndrome of autism, dementia, ataxia, and loss of purposeful hand use in girls: Rett's syndrome: report of 35 cases. Ann Neurol 14:471-479.

Hara K, Yanagihara N, Minami K, Hirano H, Sata T, Shigematsu A, Izumi F (2000) Dual effects of intravenous anesthetics on the function of norepinephrine transporters. Anesthesiology 93:1329-1335.

Hilaire G, Viemari JC, Coulon P, Simmoneau M, Bévengut M (2004) Modulation of the medullary respiratory rhythm generator by pontine noradrenergic A5 and A6 groups in rodents. Resp Physiol Neurobiol 143:187-197.

Hirota K, Kushikata T (2001) Central noradrenergic neurones and the mechanism of general anaesthesia. Br J Anaesth 87:811-813.

Hopwood SE, Stamford JA (2001) Noradrenergic modulation of serotonin release in rat dorsal and median raphe nuclei via $\alpha 1$ and $\alpha 2 \mathrm{~A}$ adrenoceptors. Neuropharmacology 41:433-442.

Ide S, Itoh M, Goto Y (2005) Defect in normal developmental increase of the brain biogenic amine concentrations in the mecp2-null mouse. Neurosci Lett 386:14-17.

Julu PO (2001) The central autonomic disturbance in Rett syndrome. In: Rett disorder and the developing brain (Kerr AM, Witt-Engerstrom I, eds), pp 131-183. New York; Oxford UP.

Julu PO, Kerr AM, Apartopoulos F, Al-Rawas S, Engerstrom IW, Engerstrom L, Jamal GA, Hansen S (2001) Characterisation of breathing and associated central autonomic dysfunction in the Rett disorder. Arch Dis Child $85: 29-37$

Kerr AM (1992) A review of the respiratory disorder in the Rett syndrome. Brain Dev 14 [Suppl]:S43-S45.

Kerr AM, Julu PO (1999) Recent insights into hyperventilation from the study of Rett syndrome. Arch Dis Child 80:384-387.

Kerr AM, Armstrong DD, Prescott RJ, Doyle D, Kearney DL (1997) Rett syndrome: analysis of deaths in the Br survey. Eur Child Adolesc Psychiatry 6 [Suppl 1]:71-74.

Kerr AM, Julu PO, Hansen S, Apartopoulos F (1998) Serotonin and breathing dysrhythmia in Rett syndrome. In: New developments in child neurology (Perat MV, ed), pp 191-195. Bologna: Monduzzi Editore.

Krauth J (1990) Distribution-free statistics, an application oriented approach. In: Techniques in the behavioral and neural sciences, p 381. Amsterdam: Elsevier.

Ladewig T, Lalley PM, Keller BU (2004) Serotonergic modulation of intracellular calcium dynamics in neonatal hypoglossal motoneurons from mouse. Brain Res 1001:1-12.

Lalley PM, Bishoff AM, Schwarzacher SW, Richter DW (1995) 5- $\mathrm{HT}_{2}$ receptor-controlled modulation of medullary respiratory neurones in the cat. J Physiol (Lond) 487:653-661.

Lekman A, Witt-Engerstrom I, Holmberg B, Percy A, Svennerholm L, Hagberg B (1990) CSF and urine biogenic amine metabolites in Rett syndrome. Clin Genet 37:173-178. 
Linner L, Wiker C, Arborelius L, Schalling M, Svensson TH (2004) Selective noradrenaline reuptake inhibition enhances serotonergic neuronal activity and transmitter release in the rat forebrain. J Neural Transm 111:127-139.

Marcus CL, Carroll JL, McColley SA, Loughlin GM, Curtis S, Pyzik P, Naidu S (1994) Polysomnographic characteristics of patients with Rett syndrome. J Pediatr 125:218-224.

Morin D, Monteau R, Hilaire G (1991) 5-Hydroxytryptamine modulates central respiratory activity in newborn rat: an in vitro study. Eur J Pharmacol 192:89-95.

Morton RE, Bonas R, Minford J, Tarrant SC, Ellis RE (1997) Respiration patterns during feeding in Rett syndrome. Dev Med Child Neurol 39:607-613.

Nielsen JB, Lou HC, Andresen J (1990) Biochemical and clinical effects of tyrosine and tryptophan in the Rett syndrome. Brain Dev 12:143-147.

Nomura Y, Segawa M, Higurashi M (1985) Rett syndrome-an early catecholamine and indolamine deficient disorder? Brain Dev 7:334-341.

Ojima K, Matsumoto K, Tohda M, Watanabe H (1995) Hyperactivity of central noradrenergic and CRF systems is involved in social isolationinduced decrease in pentobarbital sleep. Brain Res 684:87-94.

Onimaru H, Arata A, Homma I (1988) Primary respiratory rhythm generator in the medulla of brainstem-spinal cord preparation from newborn rat. Brain Res 445:314-324.

Peña F, Ramirez JM (2002) Endogenous activation of serotonin-2A receptors is required for respiratory rhythm generation in vitro. J Neurosci 22:11055-11064.

Peyron C, Luppi PH, Fort P, Rampon C, Jouvet M (1996) Lower brainstem catecholamine afferents to the rat dorsal raphe nucleus. J Comp Neurol 364:402-413.

Pudovkina OL, Cremers TI, Westerink BH (2003) Regulation of the release of serotonin in the dorsal raphe nucleus by $\alpha 1$ and $\alpha 2$ adrenoceptors. Synapse 50:77-82.

Ramirez JM, Schwarzacher SW, Pierrefiche O, Olivera BM, Richter DW (1998) Selective lesioning of the cat pre-Botzinger complex in vivo eliminates breathing but not gasping. J Physiol (Lond) 507:895-907.

Ravn K, Nielsen JB, Skjeldal OH, Kerr A, Hulten M, Schwartz M (2005) Large genomic rearrangements in MECP2. Hum Mutat 25:324.

Richter DW, Manzke T, Wilken B, Ponimaskin E (2003) Serotonin receptors: guardians of stable breathing. Trends Mol Med 9:542-548.

Riederer P, Weismer M, Wichart I, Schmidt B, Killian W, Rett A (1986) Preliminary brain autopsy findings in progredient Rett syndrome. Am J Med Genet 24:305-315.

Segawa M (1997) Pathophysiology of Rett syndrome from the standpoint of early catecholamine disturbance. Eur Child Adolesc Psychiatry 6 [Suppl 1]:56-60.

Siegel S, Catellan NJ (1989) Nonparametric statistics for the behavioral sciences, p 399. New York: McGraw-Hill.

Solomon IC (2002) Modulation of expiratory motor output evoked by chemical activation of pre-Botzinger complex in vivo. Respir Physiol Neurobiol 130:235-251.

Solomon IC (2003) Influence of respiratory network drive on phrenic mo- tor output evoked by activation of cat pre-Botzinger complex. Am J Physiol Regul Integr Comp Physiol 284:R455-R466.

Steen PA, Michenfelder JD (1979) Barbiturate protection in tolerant and nontolerant hypoxic mice: comparison with hypothermic protection. Anesthesiology 50:404-408.

St-John WM, Paton JF (2004) Role of pontile mechanisms in the neurogenesis of eupnea. Respir Physiol Neurobiol 143:321-332.

Svensson TH, Bunney BS, Aghajanian GK (1975) Inhibition of both noradrenergic and serotonergic neurons in brain by the alpha-adrenergic agonist clonidine. Brain Res 92:291-306.

Telgkamp P, Ramirez JM (1999) Differential responses of respiratory nuclei to anoxia in rhythmic brain stem slices of mice. J Neurophysiol 82:2163-2170.

Telgkamp P, Cao YQ, Basbaum AI, Ramirez JM (2002) Long-term deprivation of substance $\mathrm{P}$ in PPT-A mutant mice alters the anoxic response of the isolated respiratory network. J Neurophysiol 88:206-213.

Tryba AK, Peña F, Ramirez JM (2003) Stabilization of bursting in respiratory pacemaker neurons. J Neurosci 23:3538-3546.

Van den Veyver IB, Zoghbi HY (2000) Methyl-CpG-binding protein $2 \mathrm{mu}-$ tations in Rett syndrome. Curr Opin Genet Dev 10:275-279.

Viemari JC, Burnet H, Bévengut M, Hilaire G (2003) Perinatal maturation of the mouse respiratory rhythm-generator: in vivo and in vitro studies. Eur J Neurosci 17:1233-1244.

Viemari JC, Bévengut M, Burnet H, Coulon P, Pequignot JM, Tiveron MC, Hilaire G (2004) Phox2a gene, A6 neurons, and noradrenaline are essential for development of normal respiratory rhythm in mice. J Neurosci 24:928-937.

Viemari JC, Maussion G, Bévengut M, Burnet H, Pequignot JM, Népote V, Pachnis V, Simonneau M, Hilaire G (2005) Ret deficiency in mice impairs the development of $\mathrm{A} 5$ and $\mathrm{A} 6$ neurons and the functional maturation of the respiratory rhythm. Eur J Neurosci, in press.

Wenninger JM, Pan LG, Klum L, Leekley T, Bastastic J, Hodges MR, Feroah T, Davis S, Forster HV (2004a) Small reduction of neurokinin-1 receptorexpressing neurons in the pre-Botzinger complex area induces abnormal breathing periods in awake goats. J Appl Physiol 97:1620-1628.

Wenninger JM, Pan LG, Klum L, Leekley T, Bastastic J, Hodges MR, Feroah TR, Davis S, Forster HV (2004b) Large lesions in the pre-Botzinger complex area eliminate eupneic respiratory rhythm in awake goats. J Appl Physiol 97:1629-1636.

Woodyatt GC, Murdoch BE (1996) The effect of the presentation of visual and auditory stimuli on the breathing patterns of two girls with Rett syndrome. J Intellect Disabil Res 40:252-259.

Zanella S, Roux JC, Viemari JC, Hilaire G (2005) Possible modulation of the respiratory rhythm generator by A1/C1 neurones. Resp Physiol Neurobiol, in press.

Zoghbi HY, Percy AK, Glaze DG, Butler IJ, Riccardi VM (1985) Reduction of biogenic amine levels in the Rett syndrome. N Engl J Med 313:921-924.

Zoghbi HY, Milstien S, Butler IJ, Smith EO, Kaufman S, Glaze DG, Percy AK (1989) Cerebrospinal fluid biogenic amines and biopterin in Rett syndrome. Ann Neurol 25:56-60. 